\title{
Investigation of Reinforced Composite Aluminum Materials
}

\author{
R. Sarath Chandhara Raja*, K. Raja Karthick, V. Velmurugan \\ Department of Mechanical Engineering, Saveetha School of Engineering, Saveetha Institute of Medical and \\ Technical Sciences, Chennai, Tamil Nadu, India.
}

*Corresponding author. Email: sarathraja97@gmail.com, hallowkarthick@gmail.com, profvel@gmail.com Manuscript submitted April 12, 2018; accepted July 25, 2018.

doi: 10.17706/ijapm.2018.8.4.90-104

\begin{abstract}
The present work aims to develop Aluminum metal matrix composites by incorporating of reinforcements such that combination of best properties could be achieved. The metal base was selected was Aluminum and it is reinforced with varying volume percentage of Silicon carbide Magnesium and Fly ash. These AMC were developed by using crucible casting technique, in which predetermined reinforcement is added to the molten matrix is stirred well to obtain desired castings. The Rockwell hardness and Impact tests revealed that composite with Mg Sic Fly ash shows highest hardness value of HRB and Joules which is better than base alloy as well as tensile is more Mg and SiC Fly ash shows highest Tensile strength value. Highly reinforced composites show higher hardness and Wallop and Moderate tensile strength variations due to the agglomeration of particles. The network composite, the re enforcer material, the volume and state of the fortification, the area of the support, and the creation technique would all be able to be fluctuated to achieve required property. The composite has to be prepared by crucible casting proficiency and has to be analyzed various mechanical properties. Here we determine the hardness value of the composite material and impact strength as well as tensile strength of the material is analyzed.
\end{abstract}

Key words: Aluminum, reinforced composites, silicon carbide, surface hardness, tensile strength.

\section{Introduction}

Composite fabric are important engineering material aluminum s due to their outstanding mechanical properties Composites are texture in which the alluring properties of independent materials are joined by mechanically or metallurgically restricting them together [1]. Every one of the parts holds its structure and trademark, yet the composite for the most part has better properties. Composite Cloth offer Superior properties to conventional admixture for various application programs as they have high strength and wear impedance [2], [3]. The advancement of these materials began with the creation of constant fiber-strengthened composite [4]. The high cost and trouble of preparing these composites confined their application and prompted the improvement of irregularly strengthened composites $(\mathrm{Oz}$ emir et.al.1999).Aluminum (Al) is a shimmering white and bendable individual from the poor metal gathering of substance constituent. Al is a rich, light and solid metal which has leap forward numerous employments [5].

Like all composites, aluminum-intercellular substance composites are not a ace material but a family line of materials whose stiffness, strength, denseness, and warm and electrical effects can be custom-made. Regardless of the mutant, however, Al composites offer excellent thermal conductivity, high shear strength, excellent corrosion resistance, high temperature functioning non flammability, negligible assault by powers 
and dissolvable, and the capacity to be shaped and treated on customary hardware. [6]-[7] Silicon carbide ( $\mathrm{SiC}$ ) is made out of tetrahedral of carbon and silicon molecule with solid bonds in the vitreous silica cross section. This produces a very hard and strong material. $\mathrm{SiC}$ is not attacked by any alkali or molten salts up to $800 * \mathrm{C}[8]$.

The impact of weight level of the fortified particles on mechanical manner, for example, hardness and erosion of the composites can be investigated. The prerequisite of composite material has gained popularity in these sidereal day due to their various properties like low denseness, good wear opposition, good tensile strong point and good airfoil conclusion. Among different particulate issue utilized, Al2O3 is one of the minimum costly and low thickness support accessible in colossal amounts as strong waste via Cartesian product in ceramic flora. The Callousness strength will also be taken into consideration [9], [10]. For the achievement of the above, an experimental set up is prepared where all the necessary inputs will be made. In this work a composite is developed by adding Al203\&Graphitee in Aluminum metal by volume ratio with various percentage.

\subsection{Experimental Plan}

The proposed work approach and methodology has been elaborately shown in the flow chart.

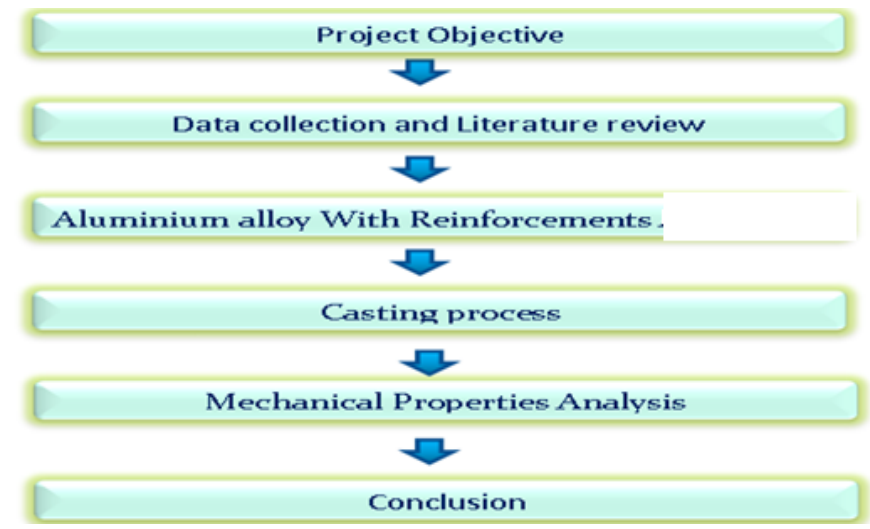

Fig. 1. Experimental plan.

\section{Materials and Methods}

\subsection{Aluminum-6061}

Table 1. Chemical Properties

\begin{tabular}{||c|c||}
\hline Atomic number & 13 \\
\hline \hline $\begin{array}{c}\text { Atomic mass } \\
\text { Plectro negativity according to } \\
\text { Pauling }\end{array}$ & $26.98154{\mathrm{~g} \cdot \mathrm{mol}^{-1}}^{-1}$ \\
\hline \hline Density & $2.7{\mathrm{~g} \cdot \mathrm{cm}^{-3} \text { at } 20^{\circ} \mathrm{C}}^{660.4^{\circ} \mathrm{C}}$ \\
\hline \hline Melting point & $2467^{\circ} \mathrm{C}$ \\
\hline \hline Boiling point & $0.143 \mathrm{~nm}$ \\
\hline \hline Vanderwaals radius & $0.05 \mathrm{~nm}$ \\
\hline \hline Ionic radius & 3 \\
\hline \hline Isotopes & 16 \\
\hline \hline Artificial isotopes & $1 \mathrm{~s}^{2} 2 \mathrm{~s}^{2} 2 \mathrm{p}^{6} 3 \mathrm{~s}^{2} 3 \mathrm{p}^{1}$ \\
\hline \hline Electronic shell & $577.4 \mathrm{~kJ}^{-\mathrm{mol}^{-1}}$ \\
\hline Energy of first ionization & \\
\hline
\end{tabular}




\begin{tabular}{||c|c||}
\hline \hline Energy of second ionization & 1816.1 kJ.mol $^{-}$ \\
\hline \hline Energy of third ionization & 2744.1 kJ.mol ${ }^{-1}$ \\
\hline \hline Standard potential & $-1.67 \mathrm{~V}$ \\
\hline \hline Discovered by & $\begin{array}{c}\text { Hans Christian } \\
\text { Oersted in } 1825\end{array}$ \\
\hline
\end{tabular}

\subsection{Aluminum}

Aluminum was the first name given to the component by Humphry Davy yet others called it aluminum and that turned into the acknowledged name in Europe. In any case, in the USA the favored name was aluminum and when the American Chemical Society bantered on the issue, in 1925, it chose to stay with aluminum. Aluminum shows delicate and lightweight metal properties. It has a dull gleaming appearance, due to a thin layer of oxidation that structures immediately when it is presented to air. Aluminum is nontoxic (as the metal) nonmagnetic and non-starting

\subsubsection{Health effects of aluminum}

Aluminum is a standout amongst the most broadly utilized metallic component and furthermore a standout amongst the most much of the time revelation substance compound $\mathrm{s}$ in the earth 's covering. Because of these reality, $\mathrm{Al}$ is generally known as a blameless compound. Yet at the same time, when one is presented to high snugness, it can cause wellbeing inconvenience. The water-dissolvable type of aluminum causes the hurtful impacts, these bit are called particle. They are typically found in an answer of aluminum in blend with other particle, for case as aluminum chlorine. The take-up of aluminum can bring home through nourishment, through breathing and by skin contact. Long lasting uptakes of significant concentrations of aluminum can lead to serious health effects, such as: Damage to the central nervous system

- Dementia

- Loss of memory

- Listlessness

- Severe trembling

Aluminum is a risk in certain working environments, such as mines, where it can be found in water. Individuals that work in production lines where nuclear number 13 is connected amid yield procedures may persevere lung issues when they take in Al tidy. Aluminum can cause issues for kidney patients when it enters the body amid kidney dialyses. Taking in of finely separated aluminum and aluminum oxide powder has been accounted for as a reason for pneumonic fibrosis and lung harm. This impact, know as Shaver's Disease, is muddled by the nearness in the breathed in line of silica and oxide of iron. May likewise be embroiled in Alzheimer's sickness.

\subsection{Aluminum Oxide}

$\mathrm{Al}_{2} \mathrm{O}_{3}$ is an electrical protector yet has a moderately high warm conductivity ( $30 \mathrm{Wm}$-unity $\mathrm{K}-1$ ) for a clay material. Aluminum oxide is in charge of the insusceptibility of metallic aluminum to weathering. Metallic aluminum is exceptionally responsive with barometrical oxygen, and a thin passivation layer of aluminum oxide ( $4 \mathrm{~nm}$ thickness) shapes on any uncovered aluminum surface.

This bed shields the metallic component from advance oxidation. The thickness and place of this oxide layer can be upgraded utilizing a procedure called anodizing. Various compounds, for example, aluminum bronzes, abuse this property by including an extent of aluminum in the amalgam to improve erosion protection. The aluminum oxide generated by anodizing is typically amorphous, but liberation assisted oxidation process such as plasma electrolytic oxidation upshot in a significant extent of crystalline aluminum oxide in the covering, upgrading its hardness. Aluminum oxide was removed the United Nation 
Environmental Protection Authority 's chemicals records in 1988. Aluminum oxide is on EPA's Toxics Button Inventory list in the event that it is a sinewy undercarriage.

\subsection{Silicon Carbide}

Si carbide ( $\mathrm{SiC}$ ), otherwise called machine borundum/karbə'rındəm/, is a concoction compound of Si and carbon with substance equation SiC., for example, car Synonyms/Hypernyms (Ordered by Estimated Frequency) of noun brake, car clutches and ceramic plates in bulletproof vests. Electronic utilizations of silicon carbide as light producing diode (Light-discharging diode) and identifiers in early radios were first exhibited around 1907, and today SiC is generally utilized as a part of high-temperature/high-voltage semiconductor gadgets. Silicon carbide with high surface region can be delivered from $\mathrm{SiO} 2$ contained in works material.

\subsubsection{Early production}

Non-methodical, less-perceived, and regularly unsubstantiated amalgamations of $\mathrm{Si}$ carbide were accounted for ahead of schedule, J. J. Berzelius's reduction of potassium fluoro silicon dioxide te by potassium (1810); Charles Mansuète Despretz's (1792-1863) passing an electric automobile automobile); Albert Colson's warmth of silicon under a stream of ethylene (1882); and Paul Schuetzenberger's warming of a diverse of silicon and silica in a graphite crucible (1881). Nevertheless, wide-scale production is credited to Edward Goodrich Dean Gooderham Dean Gooderham Acheson in 1890. Acheson was endeavoring to get ready manufactured precious stones when he warmed a blend of mud (aluminum silicate) and powdered C (carbon) in an iron bowl. He called the blue gems that framed Carborundum, trusting it to be another concoction compound of carbon and aluminum, like corundum. In 1893, Henri Moissan found the extremely uncommon normally happening $\mathrm{SiC}$ mineral while analyzing rock music tests found in the Canyon Diablo shooting star in AZ. The mineral was named moissanite in his respect. Moissan additionally incorporated $\mathrm{SiC}$ by a few courses, including: the disintegration of carbon in liquid silicon; softening a blend of calcium carbide and silica; and by lessening silica with carbon in an electric heater. Be that as it may, Moissan attributed the ace revelation of SiC to Acheson in 1903.

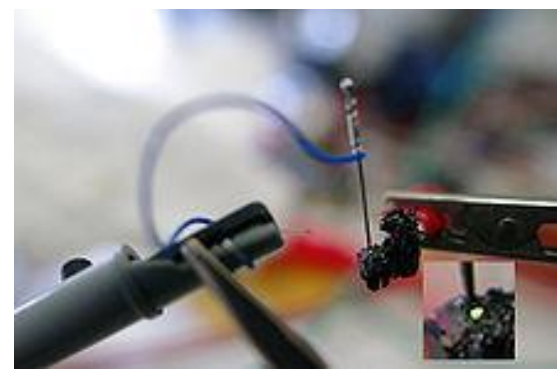

Fig. 2. A replication of H. J. Round's LED experiments.

\subsubsection{Production}

As a result of the oddment of characteristic moissanite, most silicon carbide is manufactured. It is utilized as a rough, and all the more as of late as a semiconductor and ball field simulant of jewel quality. The simplest manufacture process is to combine silica sand and carbon copy in an Acheson graphite electric immunity furnace at a heights temperature, between 1600 also, $2500{ }^{\circ} \mathrm{C}$. Fine $\mathrm{SiO}_{2}$ particles in greenery material (e.g. Timothy Miles Bindon Rice husks) can be converted to $\mathrm{SiC}$ by heating in the overabundance carbon from the organic fertilizer material. The silica smoke, which is a result of delivering silicon metal and ferrosilicon metal, additionally can be changed over to $\mathrm{SiC}$ by warming with graphite at $1500^{\circ} \mathrm{C}$. 


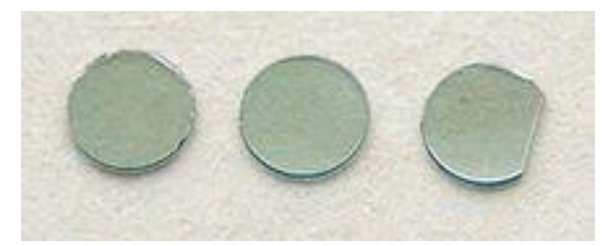

Fig. 3. Synthetic $\mathrm{SiC}$ crystals $\sim 3 \mathrm{~mm}$ in diameter.

The material shaped in the Acheson heater differs in respect, as per its space from the graphite protection warm source. Dreary, pale yellowness and green watch precious stone have the most noteworthy virtue and are discovered nearest to the protection. The shading changes to blue and dark at more prominent separation from the resistor, and these darker precious stone are less unadulterated. Pure silicon carbide can be shuffling by the so-called Lely process, in which SiC pulverization is sublimated in argon aura at 2 $500{ }^{\circ} \mathrm{C}$ and redeposited into flake-like unity crystals, sized up to $2 \times 2 \mathrm{~cm} 2$, at a slightly colder substratum. This process yields high-quality unity crystals, mostly of $6 \mathrm{H}-\mathrm{SiC}$ phase (because of high maturation temperature). A changed Lely process including acceptance warming in graphite pots yields significantly bigger single gems of quaternion inches $(10 \mathrm{~cm})$ in distance across, having a segment 81 meter bigger contrasted with the ordinary Lely process. Cubic $\mathrm{SiC}$ is typically developed by the more costly procedure of synthetic substance vapor testimony (CVD). Homoepitaxial and heteroepitaxial SiC layer can be grown employing both atomic number 31 and liquid state phase approaches. Unadulterated silicon carbide can likewise be set up by the warm deterioration of a polymer, poly(methyl silyne), under a dormant air at low temperatures.

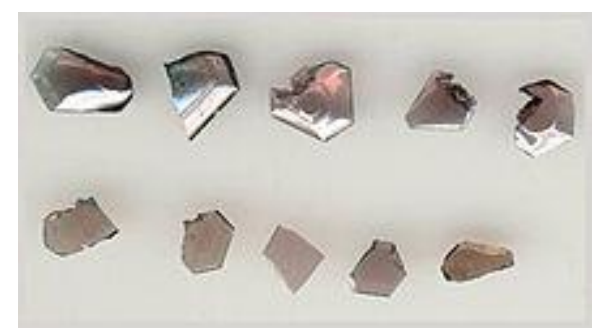

Fig. 4. Synthetic SiC Lely crystals.

With respect to the CVD outgrowth, the pyrolysis technique acting is worthwhile on the grounds that the polymer can be word frame ed into different SHAPE preceding. The pleomorphism of SiC is portrayed by a vast family of comparative crystalline development called polytypes. They are varieties of a similar concoction substance aggravate that are indistinguishable in two measurements and contrast in the third. Alpha silicon carbide ( $\alpha-\mathrm{SiC})$ is the most usually experienced polymorph; it is framed at temperature more prominent than $1700{ }^{\circ} \mathrm{C}$ and has a hexagonal precious stone social association (like Wurtzite). The beta alteration $(\beta-\mathrm{SiC})$, with a zinc blende precious stone structure (like jewel), is shaped at temperatures underneath $1700{ }^{\circ} \mathrm{C}$ [XXVII] Until as of late, the beta frame has had generally couple of business utilizes, despite the fact that there is currently expanding enthusiasm for its utilization.

Properties

\begin{tabular}{|l|c|c|c|}
\hline \multicolumn{4}{|c|}{ Properties of major SiCpolytypes } \\
\hline \multicolumn{1}{|c|}{ Polytype } & $\mathbf{3 C}(\boldsymbol{\beta})$ & $\mathbf{4 H}$ & $\mathbf{6 H}(\boldsymbol{\alpha})$ \\
\hline Crystal structure & $\begin{array}{c}\text { Zinc } \\
\text { blende }\end{array}$ & Hexagonal & Hexagonal \\
\hline Space group & $\mathrm{T}^{2}{ }_{\mathrm{d}}-\mathrm{F} 43 \mathrm{~m}$ & $\mathrm{C}^{4}{ }_{6 \mathrm{v}}-\mathrm{P} 6_{3} \mathrm{mc}$ & $\mathrm{C}^{4}{ }_{6 \mathrm{v}}-\mathrm{P} 6_{3} \mathrm{mc}$ \\
\hline
\end{tabular}




\begin{tabular}{|l|c|c|c|}
\hline Pearson symbol & $\mathrm{cF} 8$ & $\mathrm{hP8}$ & $\mathrm{hP12}$ \\
\hline Lattice constants $(\AA)$ & 4.3596 & $\begin{array}{c}3.0730 ; \\
10.053\end{array}$ & $\begin{array}{c}3.0730 ; \\
15.11\end{array}$ \\
\hline Density $\left(\mathrm{g} / \mathrm{cm}^{3}\right)$ & 3.21 & 3.21 & 3.21 \\
\hline Bandgap (eV) & 2.36 & 3.23 & 3.05 \\
\hline Bulk modulus (GPa) & 250 & 220 & 220 \\
\hline $\begin{array}{l}\text { Thermal conductivity (W } \\
\left.\mathrm{cm}^{-1} \mathrm{~K}^{-1}\right) \\
\begin{array}{l}\text { @ 300K (see [28] for temp. } \\
\text { dependence) }\end{array}\end{array}$ & 3.6 & 3.7 & 4.9 \\
\hline
\end{tabular}

Pure $\mathrm{SiC}$ is people of color less. The brown to black color of industrial product effect from iron impurities. The rainbow -like sheen of the crystallization is caused by a passivation layer of silicon dioxide that variant on the surface. The senior high sublimation temperature of $\mathrm{SiC}$ (roughly $2700{ }^{\circ} \mathrm{C}$ ) mark it valuable for course and heater parts. Silicon carbide does not soften at any known weight. It is additionally profoundly inactive synthetically. There is presently much enthusiasm for its utilization as a semiconductor material in hardware, where its high warm conductivity, high electric athletic field breakdown quality and high most extreme current thickness mark it more encouraging than silicon for powerful wind. SiC additionally has a low coefficient of warm development (quatern. 0 × 10-Captain Hicks /K) and experiences no phase transition that would cause discontinuity in thermal expansion.

\subsubsection{Electrical conductivity}

Metallic conduction has been accomplished by substantial doping with boron, aluminum or nitrogen. A urgent flight is however watched for the attractive field deportment amongst aluminum and boron doping: $\mathrm{SiC}$ : Aluminum is type-II, same as $\mathrm{Si}: \mathrm{B}$. On the opposite, $\mathrm{SiC}: \mathrm{B}$ is type-I. In push to clarify this distinction, it was noticed that $\mathrm{Si}$ site are more essential than nuclear number 6 duplicate destinations for superconductivity in $\mathrm{SiC}$. Whereas boron reliever carbon in $\mathrm{SiC}, \mathrm{Al}$ substitutes $\mathrm{Si}$ sites. Therefore, $\mathrm{Al}$ and $\mathrm{B}$ "see" different environment that might explain different prop of $\mathrm{SiC}: \mathrm{Al}$ and $\mathrm{SiC}: \mathrm{B}$.

\subsubsection{Abrasive and cutting tools}

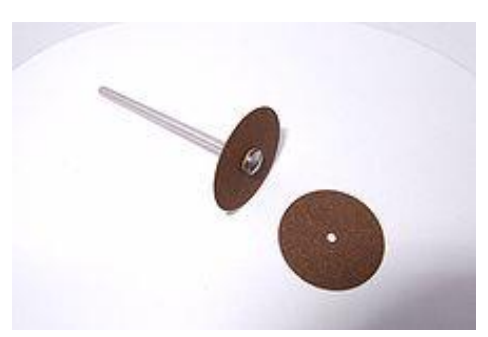

Fig. 5. Cutting tools.

In the artistic creation, Si carbide is a popular abrasive material material in modern lapidary due to the durability and low monetary value of the material. In fabrication, it is used for its hardness in abrasive machining processes such as grinding, honing, water -jet press cutting and sandblasting. Particles of nuclear number 14 carbide are covered to paper to make emery paper and the grasp measuring tape on skateboards. Growth of this laboratory-produced composite to a commercial product took only three years. In 1985, the principal business cutting instruments produced using this alumina and silicon carbide bristle fortified composite were presented by the Advanced Complex Materials Corporation (ACMC) and Greenleaf Corporation. 


\subsubsection{Structural material}

Silicon carbide is utilized for injury plates of ballistic singlet,In the 1990s, nuclear number 14 carbide was considered in a few research programs for high school -temperature gas turbines in EU, Japan and the United States. The segments were expected to supplant nickel superalloy turbine sharp edges or spout vanes. However, none of these project resulted in a output quantity, mainly because of its low impact resistivity and its low break toughness. Like other hard Synonyms/Hypernyms (Ordered by Estimated Frequency) of noun ceramic (namely alumina and boron carbide), silicon carbide is used in composite armor (e.g. Chobham armor), and in ceramic plates in bulletproof vests. Dragon Peel, which is produced by Pinnacle Armor, uses saucer of silicon carbide. Silicon carbide is used as a backup and shelving material in high temperature kiln such as for discharge ceramics, deoxyephedrine fusing, or glass casting. SiC oven racks are impressively lighter and more strong than customary alumina racks.

\subsubsection{Automobile parts}

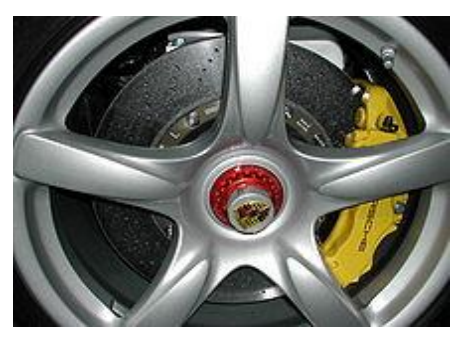

Fig. 6. Automobile parts.

The Porsche Carrera GT's C -ceramic (silicon carbide) disc brake Atomic number 14 -infiltrated C -carbon composite is used for high gear performance "fired" brake plates, as it can withstand outrageous temperatures. The silicon reacts with the graphite in the carbon-carbon composite to become carbon-fibre -reinforced silicon carbide $(\mathrm{C} / \mathrm{SiC})$. These circles are utilized on some street going games autos, including the Porsche Carrera GT, the Bugatti Veyron, the Chevrolet Corvette ZR1, Bentleys, Ferraris, Lamborghinis, and some specific elite Audis. Silicon carbide is likewise utilized as a part of a sintered frame for diesel particulate channels.

\subsubsection{Electric systems}

These Synonyms/Hypernyms (Ordered by Estimated Frequency) of noun device must exhibit high resistance until the electric potential across them orbit a certain verge Vermont, at which peak their resistance must drop to a lower point and maintain this level until the applied voltage drops below VT.

When a lightning tap to the rail crease raises the line emf sufficiently, the SiC newspaper column will conduct, allowing strike current to pass harmlessly to the earth rather than along the capacity line. Such SiC tower proved to conduct significantly at normal power-line operating voltages and thus had to be placed in serial publication with a spark break. This start hole is ionized and rendered conductive when lightning raises the voltage of the electrical cable chief, along these lines successfully associating the SiC section between the power conduit and the earth. Start holes utilized as a part of lightning arrester snare $s$ are untrustworthy, either shortcoming to strike a curve when required or neglecting to kill subsequently, in the last claim due to textile failure or contamination by dust or salinity. Exercise of SiC segments was initially proposed to wipe out the requirement for the start hole in a lightning arrester. Interference SiC lightning arrester were utilized as lightning-security apparatus and sold under GE and Westinghouse mark names, among others. The gapped SiC arrester has been largely displaced by no-gap varistors that use columns of zinc oxide pellet

\subsubsection{Electronic circuit elements}




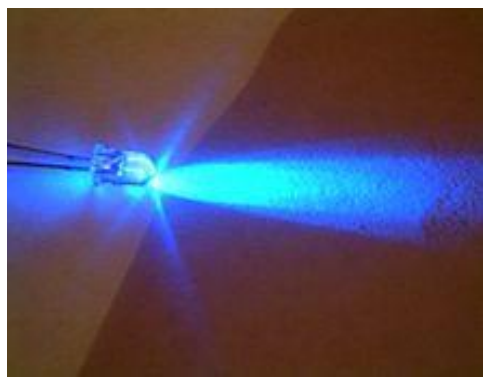

Fig. 7. Ultraviolet LED.

\section{Power electronic devices}

Silicon carbide is a semiconductor in investigate and early large scale manufacturing giving favorable circumstances to quick, high-temperature and/or high-voltage gimmick. First devices available were Schottky crystal rectifier, followed by Join -gate FETs and MOSFETs for high-power switch. Bipolar transistors and thyristors are at present created.

A Major issue for SiC business message ization has been the end of inadequacy: edge breakdown, screw separations (both opening and shut center), triangular deformities and basal plane dislocations. therefore, gadgets made of $\mathrm{SiC}$ gem at first showed needy individuals turn around blocking working however specialists have been probably discovering arrangements to improving the breakdown carrying into action. Apart from crystal quality, problems with the user interface of $\mathrm{SiC}$ with silicon dioxide have hampered the development of SiC-based business leader MOSFETs and insulated-gate bipolar transistors. Despite the fact that the concoction component is as yet hazy, nitridation has significantly lessened the imperfections causing the interface problems. In 2008, the primary business JFETs evaluated at $1200 \mathrm{~V}$ were acquainted with the store, followed in 2011 by the main business MOSFETs appraised at $1200 \mathrm{~V}$. Beside SiC switches and SiC Schottky crystal rectifier (also Schottky barrier diode SDB) in the popular T0-247 package, companies started even earlier to implement the uncovered chips into their energy modules. SiC SBD precious stone rectifier discovered wide market spread being utilized as a part of PFC visit and IGBT control modules.

\subsubsection{LEDs}

The generation was soon halted on the grounds that gallium nitride demonstrated 10-100 times brighter release. This contention in proficiency is expected to the troublesome circuitous bandgap of SiC, though GaN has a direct bandgap which supports light emanation. However, SiC is still one of the important LED components - it is a popular substrate for growth GaN 5 senses of device, and it also serves as a warmth spreader in heights -business leader LEDs.

\subsubsection{Astronomy}

The Low warm development coefficient, high meticulousness, unbending nature and warm conductivity make silicon carbide an alluring mirror material for cosmic telescopes. The growth technology (chemical substance vapor deposition) has been scaled up to green groceries disks of polycrystalline silicon carbide up to $3.5 \mathrm{~m}$ in distance across, and a few telescopes (like the Herschel Space Scope) are as of now outfitted with SiC optics.

\subsubsection{Applications}

1) advanced printed circuit board

2) microelectronic packaging

3) radiofrequency and microwave packaging

4) optoelectronic packaging

\subsubsection{Typical Properties}




\begin{tabular}{|c|c|}
\hline Density, $\mathrm{g} / \mathrm{cm}^{3}$ & $2.7-3.00$ \\
\hline Thermal Conductivity, $\mathrm{W} / \mathrm{m} \cdot \mathrm{K}$ & $170-200$ \\
\hline Thermal Expansion Coefficient, $\mathrm{E}-6 \mathrm{~K}^{-1}$ & tailor-made from 6.5 to 9.5 \\
\hline Electrical Resistivity, $\cdot \mathrm{cm}$ & $30-50$ \\
\hline Bending Strength, $\mathrm{MPa}$ & $350-500$ \\
\hline Elastic Modulus, $\mathrm{GPa}$ & $200-230$ \\
\hline
\end{tabular}

\subsection{Fly Ash}

Fly ash tree tree tree tree, also known as fluke -ash, is one of the residues generated in combustion, and complift $s$ the fine mote $s$ that advance with the pipe gases. Fiery debris which does not rise is named backside powder. In a modern setting, rainfly front fiery remains more often than not alludes to cinder delivered amid ignition of coal. Fly fiery remains is for the most part caught by electrostatic precipitators or other molecule filtration gear before the vent gases ambit the light stack of coal-let go control modern plant, and together with base cinder expelled from the base of the heater is in this slip mutually known as coal slag. Contingent on the source and cosmetics of the coal being scorched, the segments of fly slag change significantly, however all fly fiery debris incorporates generous total of silicon dioxide (SiO2) (both shapeless and crystalline) and nuclear number 20 oxide ( $\mathrm{CaO}$ ), both being endemic fixings in numerous coal-bearing tilt strata. Toxic segment part rely on the specific coal bed cosmetics, yet may incorporate at least one of the accompanying components or importance in amounts from follow aggregate of cash to a few percent : arsenic, beryllium, B , cadmium, chromium , hexavalent chromium, cobalt, lead, manganese, mercury, Mo , selenium, strontium, thallium, and vanadium, alongside dioxins and PAH mixes. Previously, fly fiery debris was for the most part discharged into the air, yet contamination control hardware ordered in Holocene age 10 now require that it be caught preceding discharge. In the US, fly powder is by and large put away at coal control plants or put in landfill. Around $43 \%$ is recycled, frequently used to supplement Portland bond in solid yield. Some have communicated wellbeing worries about this. In some cases, such as the burn of solid waste to create electrical energy ("resource recovery" facilities a.k.a. squander to-vitality offices), the fly cinder may contain higher phase of pollution than the base fiery remains and blending the fly and base slag together brings the corresponding levels of defilement inside the range to qualify as nonhazardous squander in an unsafe waste.

\section{Experimental Set Up Used and Casting Requirement}

Table 2. List of Equipment Used for Crucible Casting Operation

\begin{tabular}{|c|c|}
\hline SL.NO & EQUIPMENT USED \\
\hline 1 & Power Hacksaw \\
\hline 2 & Graphite crucible mould \\
\hline 3 & Graphite stirrer \\
\hline 4 & Pit Furnace \\
\hline 5 & Stainless steel \\
\hline
\end{tabular}

\subsection{Pit Furnace}

Pit heater was utilized to warm the material to wanted temperatures by conduction, convection, or blackbody illumination from electrical protection warming framework components. A fossa heater in recorded use is a heater in which the field material is disconnected from the fuel and the greater part of the results of burning including throttle and flying ash.

\subsection{Mixingratio}


In thisr project Aluminum and silicon carbide, Graphite mixed below mentioned categories

$\begin{array}{ccc}\text { Sample1: AL 90\% } & \text { SIC 5\% } & \text { FLY ASH5\% } \\ \text { Sample2: AL 85\% } & \text { SIC10 \% } & \text { FLY ASH5\% } \\ \text { Sample3: AL 80\% } & \text { SIC10 \% } & \text { FLY ASH10\% }\end{array}$

\subsubsection{Material requirement finding method}

Cylindrical Specimen size- $2.5 \mathrm{~cm}$ dia-\&Length- $30 \mathrm{~cm}$

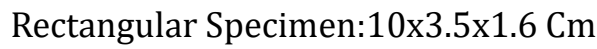

Volume-3.14/4*252*320*percentage of composite*density*percentage of excess of material

\section{Model Calculation For Ratio: 1}

$=\pi \mathrm{d}^{2} \mathrm{~L}$

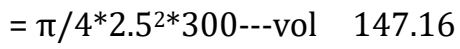

Plate: $\mathrm{L}^{*} \mathrm{~B}^{*} \mathrm{H}$

$=10 * 3.5 * 106=56$

$\mathrm{Al}=589 * 2.7 * 0.95----377 \mathrm{~g}+30 \%$

$=113 / 500 \mathrm{~g}-\mathrm{rod}$

Plate:56*2.7-151.2*0.3\% extra $1431+45 \mathrm{~g}-200 \mathrm{~g}$

$500+200=700 \mathrm{~g}$ Rod + plate

Ratio-1 $700 \mathrm{~g}$ for 2 nos

Like that remaining calculation were done on same manner. Aluminum metal materials or simply complex plant are combinations of materials. They are comprised of consolidating at least two materials such that the subsequent materials have certain plan properties on enhanced properties. The Aluminum amalgam composite materials consist of specific quality, high particular firmness, more warm dependability, more consumption and wear protection, high exhaustion vivacity .AlSiC, articulated 'alsick' is a metal network composite comprising of aluminum framework with silicon carbide particles. It has high warm conductivity (180- $200 \mathrm{~W} / \mathrm{m} \mathrm{K})$ and it is essentially utilized as a part of microelectronics as substrate for control semiconductor gadgets and high thickness multichip modules, where it helps with evacuation of waste warmth.

The mechanical attribute of aluminum alloys reinforced with ceramic particulates are known to be influenced by the particle sizing and the volume fraction.

\subsection{Casting}

In this project we have used George Sand mold molding for produce the requirement size of it. Sand give, additionally referred to a role as George Sand shaped embellishment, is a metal throwing outgrowth portrayed by utilizing George Sand as the form material. It is moderately shoddy and adequately hard-headed notwithstanding for steel metalworks utilize. An appropriate holding specialist (normally Lucius DuBignon Clay) is blended or happens with the sand. The blend is saturated with water to create quality and pliancy of the mud and to make the total appropriate for trim. The full term "sand throwing" can likewise allude to a throwing delivered by means of the sand throwing process. Sand castings are delivered in specific assembling plant called metalworks. More than $70 \%$ of every single metal throwing are delivered by means of a sand throwing process.

\section{Basic Process}

There are six steps in this process:

1) Place a tradition in sand to make a shape.

2) Incorporate the example and sand in a gating framework.

3) Disengage the pattern.

4) Fill the mildew cavity with molten metal.

5) Allow the metallic element to cool. 
6) Break away the Amandine Aurore Lucie Dupin mold and remove the molding.

\subsection{Steps}

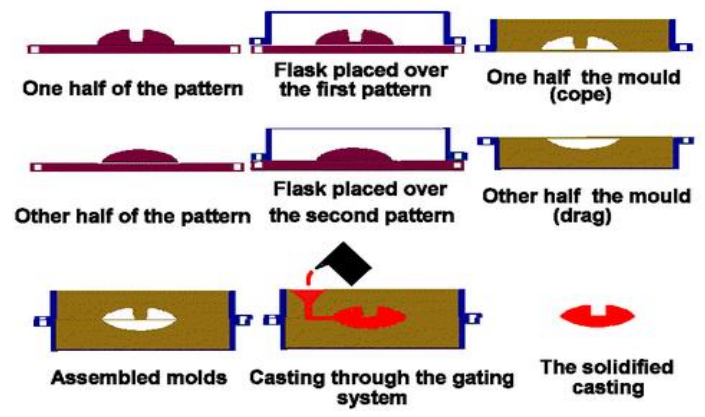

Fig. 8. Procedure.

\subsection{Furnace}

Perdition furnace are those furnace that are applied for oestrusing various metal or alloys of metals. They are accessible in different sizes and are either firearm let go or fuel let go. They can work at different temperatures and are outlined such that the warmth misfortune is minimum. Safe operation, is an important facet of this furnace because the fan and heating chemical element are separate from the load bed bedroom. Because of this wrong from incidental contact is wiped out. Metal coating is utilized as a part of the whole oeuvre chamber which gives the heater most extreme strength.

Following are the features of pit furnace:

- They can withstand ceaseless task.

- Some of the pit heater have connect to kind of entryway/answer cover.

- Temperature is distributed uniformly.

- For longer element life heating constituent operate on low surface load.

- Most recent stone pit heater utilizes programmed temperature control by advanced controller with wellbeing go down non-showing controller

- The heater is all around protected by utilizing bore blocks/earthenware fiber for vitality preservation.

- Furnace operation is safe because of the use of condom interlock and protection devices.

- Using fan motor with shaft and sword of heating system resistant material with water cooled heading air circulation is effected.

\section{Advantages}

- The pit furnace has high efficiency.

- Temperature is distributed uniformly.

- The operation is less complex.

- The maintenance is simple and cost efficient

In our labor Aluminum metal ground substance composite material melted coal fired pit furnace. Mentioned Ration were melted very successfully.

\section{Testing and Results}

\subsection{Rockwell Hardness Test}

1) Rockwell Stiffness systems use a direct readout machine determining the hardness numeral based upon the depth of penetration of either a diamond distributor point or a steel Lucille Ball. Deep 
penetration indicated a material having a David Low Rockwell Hardness number.

2) In any case, a low entrance shows a stuff having a high Rockwell Hardness figure. The Rockwell Hardness bit depends on the distinction in the profundity to which a penetrator is driven by a clear light or "minor" load and an unequivocal overwhelming or "Major" load.

3) The ball penetrator are chucks that are made to clutch $1 / 16$ " or $1 / 8$ " diameter hardened blade balls Additionally accessible are $1 / 4$ " and $1 / 2$ " ball penetrators for the testing of gentler material.

4) There are two sorts of iron blocks that are utilized on the Rockwell hardness analyzers. The flat tire faceplate theoretical account are used for flat specimen. The " $\mathrm{V}$ " type anvils wait round specimens firmly.

5) Test blocks or calibration blocks are flat steel or brass blocks, which have been tested and marked with the weighing machine and Norman Rockwell number. They should be used to impediment the accuracy and calibration of the quizzer frequently.

\section{Using the "C" Scale;}

1) Using a Diamond indenter

2) Major load: $107.5 \mathrm{Kg}$ f, smaller load: $10 \mathrm{Kg}$

3) Utilized in metallic alloy materials.

4) Don't use on strengthened steel

\section{Graph for Hardness}

Hardness Value

\begin{tabular}{|c|ccc|c|}
\hline S.No & \multicolumn{3}{|c|}{ Material } & HRB \\
\hline 1 & AL $90 \%$ & SIC 5\% & FLY ASH5\% & 74 \\
\hline 2 & AL $85 \%$ & SIC10 \% & FLY ASH5\% & 82 \\
\hline 3 & AL $80 \%$ & SIC10 \% & FLY ASH10\% & 86 \\
\hline
\end{tabular}

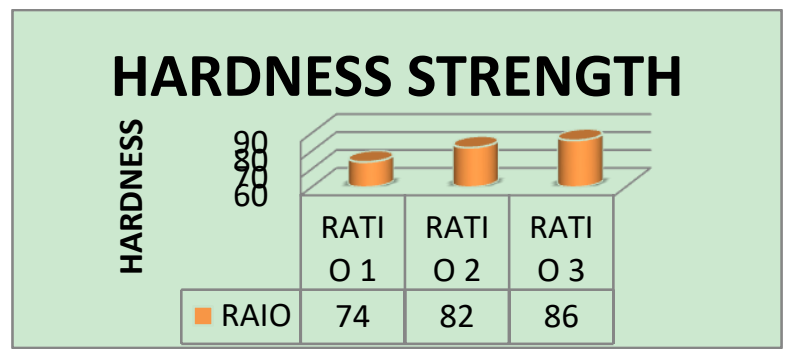

Fig. 9. Hardness test.

\subsection{Impact Test}

Izod encroachment force examination is an ASTM standard method of determining encroachment strong power point. An indented inspecting is by and large used to decide clobber quality. Stun is a critical marvel in representing the life of an anatomical structure. In the case of aircraft, impingement can take piazza by the bird hitting the plane while it is cruising, during take - off and landing there is impact by the junk present tense on the runway An arm cargo hold at a specific top (constant potential vim) is released. The arm hits the sample and breakout it. From the free vitality consumed by the example, its effect quality is determined. The Second Earl of Guilford American standard for Izod Impact examination is ASTM DII 56. Alternatively, the results may be reported as energy lost per unit crossbreed -sectional area at the notch $\left(\mathrm{J} / \mathrm{m}^{2}\right.$ or $\left.\mathrm{ft}-\mathrm{lb} / \mathrm{in}^{2}\right)$. In Europe, ISO 1octad 0 strategy acting are utilized and comes about are construct just in light of the cross-sectional zone at the indent $\left(\mathrm{J} / \mathrm{m}^{2}\right)$. The dimensions of a standard specimen for ASTM D256 are quartet x 12.7 x 3.2 millimeter ( $2.5 "$ x $0.5 "$ x 1/8"). The most common specimen thickness is 3.2 
$\mathrm{mm}(0.125 ")$,

\begin{tabular}{|c|c|c|}
\hline S.No & Composition & $\begin{array}{c}\text { Impact Strength } \\
\text { Joules }\end{array}$ \\
\hline 1 & $\begin{array}{c}\text { AL 90\% SIC 5\% } \\
\text { FLY ASH5\% }\end{array}$ & 8 \\
\hline 2 & $\begin{array}{c}\text { AL 85\% } \\
\text { SIC10 \% FLY } \\
\text { ASH5\% }\end{array}$ & 9 \\
\hline 3 & AL 80\% FLY & 13 \\
& $\begin{array}{c}\text { SIC10 \% FH10\% } \\
\text { ASH }\end{array}$ & \\
\hline
\end{tabular}

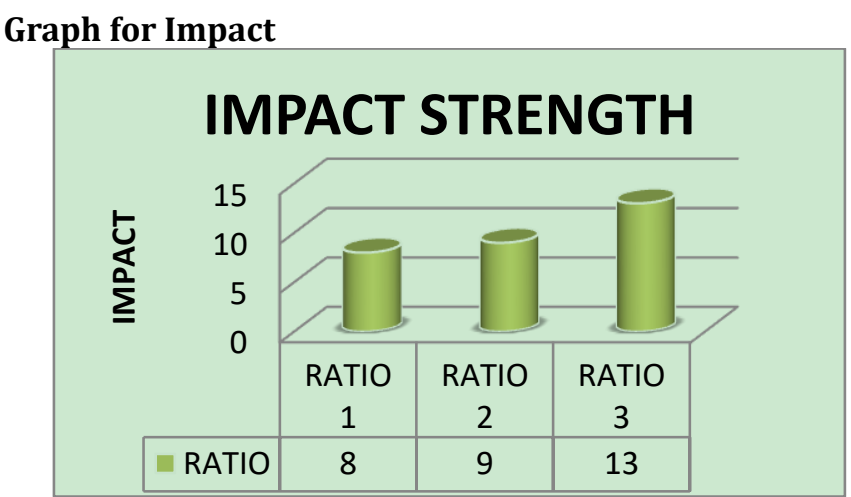

Fig. 10. Impact strength.

\subsection{Tensile Test and Elongation}

Friction processed reefer are evaluated for their mechanical characteristics through tensile psychometric testing. A tensile test helps determining tensile property such as tensile strength, issue strength, percentage of elongation, and percentage of reduction in orbit and modulus of versatility. The welding parameter were arbitrarily choose inside the range accessible in the machine. The junction were made with random parameters and evaluate tensile strength and burn mark off. At that point the joints were made and assess the mechanical and metallurgical qualities. The erosion welded examples were set up according to the ASTM principles. The test was carry out in a universal joint testing machine (UTM) 40 tones FIE make.

\section{Elongation}

Contortion in continuum shop mechanic is the shift of a sound box from a character reference configuration to a current configuration. An arrangement is a set containing the places of all particles of the physical structure. Contrary to the common definition of contortion, which implies distortion or variety in human consistency, the continuum mechanics definition includes rigid consistence movement where shape changes don't occur A miss happening might be caused by outside burdens, body powers, (for example, gravity or electromagnetic powers), or temperature changes inside the body. Tune is a verbal portrayal of disfigurement in full term of relative deracination of particles in the body. Diverse equal decisions might be made for the outflow of a strain region relying upon whether it is characterized regarding the underlying or the last design of the body and on whether the metric unit tensor or its double is considered. In a continuous body, a deformation discipline of operations answers from a emphasis field induced by applied forces or is due to changes in the temperature field inside the body. The relation back between tension and induced strains is expressed by constitutive equations, e.g Robert Hooke 's law for straight flexible band fabric s. Disfigurements which are recuperated after the pressure field has been expelled are called flexible contortion. For this situation, the continuum totally recoups its unique arrangement. On the other scaffold player, irreversible disfigurements stay even after anxieties have been expelled. One unpredictable of irreversible distortion is plastic twisting, which happens in material bodies after burdens have accomplished a specific edge esteem known as the versatile impediment or natural product stretch, and are the aftereffect of faux pas, or disengagement mechanics at the nuclear level. Another character of irreversible distortion is thick twisting, which is the irreversible piece of visco versatile disfigurement.

\subsection{Tensile Strength}


(Dia Of The Rod-16mm)-Breaking Load

\begin{tabular}{|c|c|c|c|c|c|c|c|c|c|c|c|}
\hline \multirow{2}{*}{ Identi } & Dia & CSA & YL & YS & $\mathrm{TL}$ & TS & IGL & FGL & \multirow{2}{*}{$\% \mathrm{E}$} & \multirow[b]{2}{*}{ FD } & \multirow[b]{2}{*}{$\% \mathrm{RA}$} \\
\hline & $\mathrm{mm}$ & $\mathrm{mm} 2$ & $\mathrm{kN}$ & $\mathrm{N} / \mathrm{mm}^{2}$ & $\mathrm{kN}$ & $\mathrm{N} / \mathrm{mm}^{2}$ & $\mathrm{~mm}$ & $\mathrm{~mm}$ & & & \\
\hline A1 & 16.2 & 207.2 & 19.5 & 94.29 & 24 & 115.8 & 100 & 109.8 & 9.84 & 14.3 & 22.9 \\
\hline $\mathrm{A} 2$ & 16 & 200.4 & 18.4 & 91.62 & 25 & 124.6 & 100 & 108.6 & 8.62 & 14.1 & 22.6 \\
\hline A3 & 16.1 & 202.4 & 19.4 & 95.95 & 24.2 & 119.5 & 100 & 110.7 & 10.7 & 14.4 & 19.7 \\
\hline
\end{tabular}

\section{Elongation}

Sample 1 Composite $1-\mathbf{9 . 8 4 m m}$

Sample 2 Composite 2-:8.62mm

Sample 3 Composite $3 \mathbf{- 1 0 . 6 5 m m}$

Graph for Tensile

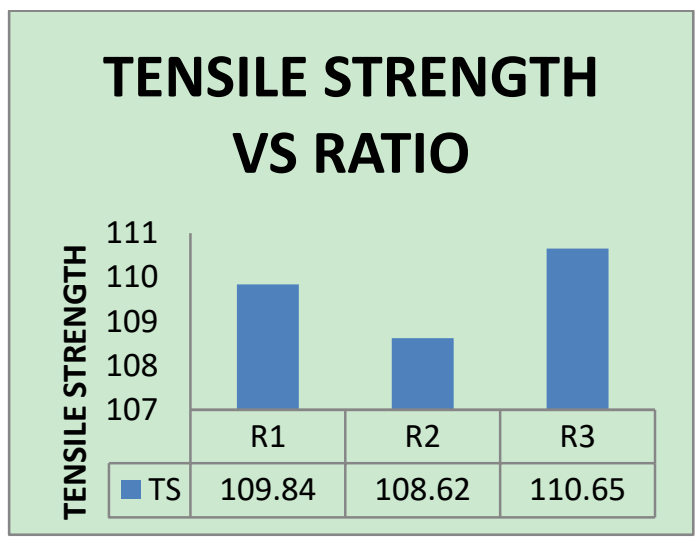

Fig. 11. Tensile strength vs ratio.

MMC has been used in applied science application in broad way because of their mechanical and physical properties. They are broadly used in the landing field of automobile and aerospace because of their senior high school strength to weight ratio, sparkle er weight, Lower cost, and trade good behavior. In present study the mechanical behavior of atomic number 13 metal ground substance composite and SiC has been analyzed. Brake Stamp pad is manufactured by route of casting which is widely preferred because of its David Low cost, high volume production, ease of operation, sustainability and attractive manufacturing process. Brake cushions are created with light admixture Aluminum 6061 fortified with SiC \& Fly ash to expand the quality and wear protection and investigate the benefit of low tightness of the matrix.

\section{Conclusion}

These castings were studied for behavior and subjected to mechanical testing to study the effects of various reinforcements. The Rockwell hardness and impact tests revealed that composite with $10 \%$ Sic $10 \%$ Fly ash shows highest hardness value of $95 \mathrm{HRB}$ and higher impact value 13J and Tensile strength also higher value obtained $\left(110.65 \mathrm{n} / \mathrm{mm}^{2}\right)$ which is better than base alloy as well as tensile is more $10 \%$ Sic $5 \%$ Fly ash shows highest Tensile strength value $102.63 \mathrm{~N} / \mathrm{mm}^{2}$.Highly reinforced composites show higher variations due to the agglomeration of particles. Hence we can conclude that the durability increases for composite aluminum materials to base aluminum comparatively.

\section{References}


[1] Bhagyashekar, M. S., et al. (2010). Studies on Al6061-SiC and Al7075-Al203 metal matrix composites. J. Miner. Mater. Charact. Eng.. 9, 43-55.

[2] Kudari, S., et al. (2015). Study on the effects of sic particles on tensile properties for al/sic composites. International Journal of Science, Technology \& Management, 4, 1477-1483.

[3] Suryanarayanan, K., Praveen, R., \& Srinivasan, R. (2013). Silicon carbide reinforced aluminum metal matrix composites for aerospace applications: A literature review. International Journal of Innovative Research in Science. Engineering and Technology, 2, 6336-6344.

[4] Jayashree, P. K., et al. (2013). Review on effect of silicon carbide (SiC) on stir cast aluminum metal matrix composites. Int J Curr Eng Technol., 3, 1061-1071.

[5] Sahin, Y. (2003). Preparation and some properties of SiC particle reinforced aluminum alloy composites. Materials \& Design, 24, 671-679.

[6] Sakthivel, A., et al. (2008). Production and mechanical properties of SiC particle-reinforced 2618 aluminum alloy composites. Journal of Materials Science, 43, 7047-7056.

[7] Das, S., et al. (2010). Experimental investigation on the effect of reinforcement particles on the forgeability and the mechanical properties of aluminum metal matrix composites. Materials Sciences and Applications, 01.

[8] Das, S., et al. (2010). Experimental analysis on the forgeability and the mechanical properties of aluminum silicon carbide metal matrix composites. 69th World Foundry Congress 2010.

[9] Kumar, B. R., Kumar, S., \& Das, S. (2012). Fabrication and characterization of $7075 \mathrm{Al}$ alloy reinforced with SiC particulates. The International Journal of Advanced Manufacturing Technology, 65.

[10] Verma, N., et al. (2017). Review on effect of various types of reinforcement particles on mechanical behavior of 6061 and 7075 aluminium alloy matrix composite.

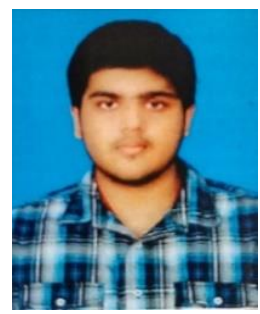

R. Sarath Chandhara Raja had completed his CBSE-10 th and $12^{\text {th }}$ at bhakthavatsalam vidyashram in Chennai, and then he is pursuing his final year mechanical engineering at Saveetha School of Engineering in Chennai.

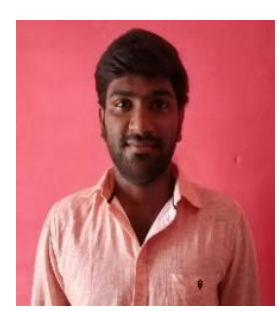

K. Rajakarthick had completed his SSC at Bharath Montessori matric higher sec. School in Ilanji and had completed his $12^{\text {th }}$ at Ramasamy Pillai School, and then he is pursuing his final year mechanical engineering at Saveetha School of Engineering in Chennai.

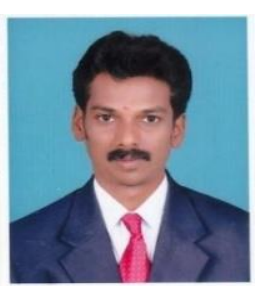

V. Velmurugan has completed the UG from Madras University and the PG from PSG technology in Bharathiyar University and the Ph.D in Anna University, Chennai. He has 17 years teaching experience and as a project consultant for 5 years and various design engineering project. 